\title{
PENERAPAN METODE WEIGHTED PRODUCT SEBAGAI PENDUKUNG KEPUTUSAN SELEKSI KARYAWAN BARU PT. HI-LEX INDONESIA
}

\author{
Frieyadie $^{1}$; Fariati $^{2}$ \\ aSistem Informasi, STMIK Nusa Mandiri \\ Jl. Damai No. 8, Warung Jati Barat (Margasatwa), Jakarta 12540, Indonesia \\ 1 frieyadie@nusamandiri.ac.id (Corresponding author) \\ 2fariati1996@gmail.com
}

\begin{abstract}
ABSTRAK
Penerimaan karyawan dalam setiap perusahaan adalah kegiatan yang senantiasa dilakukan dalam suatu periode tertentu atau secara insidentil. Proses perekrutan ini memerlukan proses pengambilan keputusan sebagaimana halnya proses pengambilan keputusan lainnya dalam konteks yang berbeda Pada konteks penerimaan karyawan, sejumlah calon karyawan mengajukan diri dengan menyediakan segala berkas yang dipersyaratkan dan mereka juga mungkin diuji secara tertulis atau wawancara. Adapun metode yang saya gunakan dalam penelitian ini dengan menggunakan weighted product dan diperhitungkan secara kuantitatif. Dari hasil penelitian yang telah dilakukan adalah diperoleh 1 calon karyawan terbaik dari dari jumah sampel sebanyak 10 orang. Berdasarkan hasil penelitian yang dilakukan dimana Pemilihan bobot penilaian dapat dikembangkan dengan kriteria-kriteria yang lain sesuai dengan kebutuhan perusahaan, pengunaan metode Weighted Product lebih akurat untuk mendapatkan hasil perhitungan bobot kriteria, Hasil perhitungan dengan menggunakan metode Weighted Product, dengan acuan kriteria tes wawancara, tes psikotes, tes kesehatan, pengalaman kerja, pendidikan terakhir, usia dan penampilan, maka terpilih 1 (satu) orang calon karyawan, yang bernama Sukirman yang akan menjadi karyawan di PT.Hi-Lex Indonesia.
\end{abstract}

Kata Kunci: Sistem Pendukung Keputusan, Seleksi karyawan baru, Weighted Product (WP)

\begin{abstract}
Acceptance of employees in each company is an activity that is always carried out in a certain period or incidentally. This recruitment process requires a decision-making process as well as other decision-making processes in different contexts. In the context of employee recruitment, a number of prospective employees submit themselves by providing all required files and they may also be tested in writing or interview. The method that I use in this study is using a weighted product and quantitatively calculated. From the results of the research that has been done is obtained the best candidates from 10 households. Based on the results of the research conducted where the selection of assessment weights can be developed with other criteria according to company needs, the use of the Weighted Product method is more accurate to obtain the calculation of criteria weight, the results of calculations using the Weighted Product method, by reference to interview test criteria, tests psychological test, health test, work experience, recent education, age and appearance, then 1 (one) prospective employee is chosen, named Sukirman who will become an employee at PT.Hi-Lex Indonesia.
\end{abstract}

\section{Keywords: Decision Support System, Selection of new employees, Weighted Product (WP)}

\section{PENDAHULUAN}

Penerimaan karyawan dalam setiap perusahaan adalah kegiatan yang senantiasa dilakukan dalam suatu periode tertentu atau secara insidentil. Proses perekrutan ini memerlukan proses pengambilan keputusan sebagaimana halnya proses pengambilan keputusan lainnya dalam konteks yang berbeda. Pada konteks penerimaan karyawan, sejumlah calon karyawan mengajukan diri dengan menyediakan segala berkas yang dipersyaratkan dan mereka juga mungkin diuji secara tertulis atau wawancara. Pemilihan sejumlah calon karyawan ini terkadang menjadi sesuatu yang sulit dikala jumlah pendaftar itu banyak dari berbagai ragam latar belakang.

PT. Hi-Lex Indonesia menyeleksi karyawan baru dari segi tes wawancara, tes psikotes, tes kesehatan, pengalaman kerja, pendidikan terakhir, 
usia dan penampilan.

Saat ini faktor utamanya perusahaan sering kali mendapatkan karyawan yang tidak sesuai dengan bobot yang telah ditentukan disebabkan karena perusahaan tidak memiliki bobot tetap, kesulitan dalam memiliki karyawan yang tidak sesuai dengan kriteria dan masih banyak juga masalah yang lainnya (Fajarianto, Iqbal, \& Cahya, 2017)

Metode Weighted Product merupakan sebuah metode didalam penentuan sebuah keputusan dengan cara perkalian untuk menghubungkan rating atribut (Moenir \& Budiyanto, 2018), dimana rating setiap atribut harus dipangkatkan terlebih dahulu dengan bobot atribut yang bersangkutan (Mirawati, Hikmah, \& Wiguna, 2018).

Proses admistrasi pada penerimaan karyawan saat ini masih manual (Moenir \& Budiyanto, 2018), (Putra \& Ferdiansyah, 2018) karena perusahaan masih harus memilih curriculum vitae pada masing-masing calon karyawan dan harus mengintputkan data masingmasing calon karyawan satu-persatu kedalam komputer. Hal tersebut, terkadang membuat terjadinya subjektifitas (Amalia \& Utami, 2018) pemilihan dan kesalahan pengimputan data (Agustin \& Kurniawan, 2015), (Ariani, 2017), Maka diperlukan sebuah sistem penudukung keputusan yang dapat digunakan untuk menyeleksi calon karyawan berdasarkan kriteria yang ada dalam menentukan seleksi karyawan (Rahmawati \& Astuti, 2018).

Data calon karyawan baru belum memiliki kriteria dan bobot yang tepat, proses penerimaan karyawan barunya memerlukan waktu yang cukup lama, dan dalam proses perhitungannya masih belum akurat (Ismail \& Nurjaya, 2016). Tujuan penelitian ini diharapkan dapat untuk mendapatkan bobot kriteria kinerja karyawan baru, agar tidak terjadi lagi pemilihan dan kesalahan pengimputan data, dan tidak terjadi lagi kesalahan dalam menginput data karyawan baru

\section{METODE PENELITIAN}

\section{Tahapan Penelitian}

Dalam hal ini akan di uraikan mengenai langkah-langkah yang dilakukan untuk mendapatkan metodologi penelitian yang merupakan suatu tahapan yang harus diterapkan agar penelitian dapat dilakukan dengan terarah dan memudahkan dalam melakukan analisa terhadap permasalahan yang ada. Tahapan penelitian tentang Sistem Pedukung Keputusan Seleksi Karyawan Baru di PT. Hi-Lex Indonesia Dengan Metode Weighted Product (WP) secara umum dapat digambarkan melalui flowchart dan dapat dilihat pada Gambar 1.

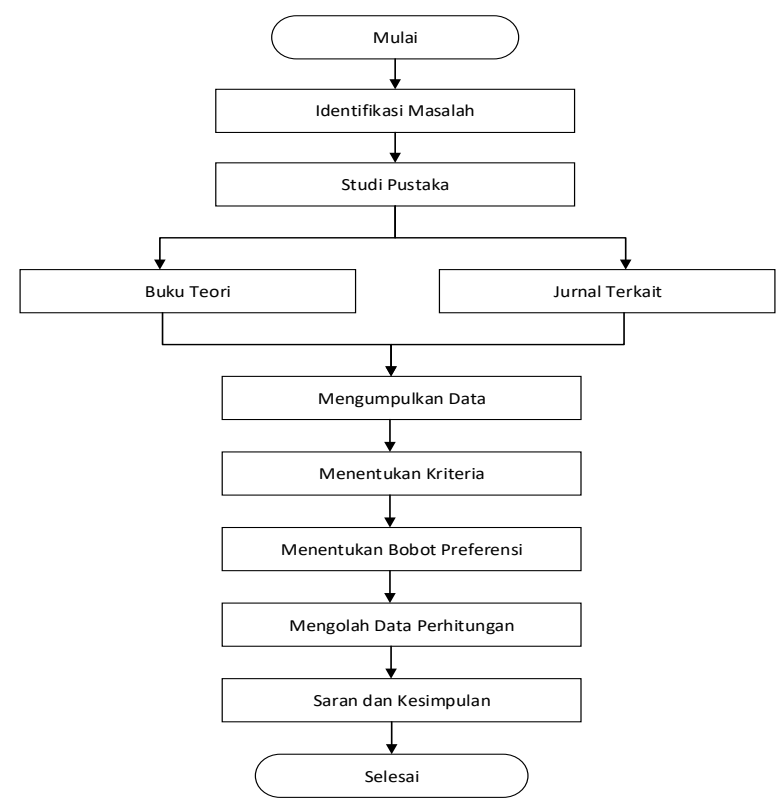

Gambar 1. Flowchart Tahapan Penelitian

Sumber: Hasil Pengolahan Analisa Penulis

a. Identifikasi Masalah

Mengidentifikasi masalah yang akan dibahas, berkaitan dengan Sistem Pendukung Keputusan Seleksi Karyawan Baru PT. Hi-Lex Indonesia Dengan Metode Weighted Product (WP) sesuai dengan informasi yang diperoleh.

b. Studi Pustaka

Penulis mempelajari buku-buku serta jurnal penelitian sebelumnya yang berkaitan dengan Sistem Pendukung Keputusan metode Weighted Product (WP).

c. Mengumpulkan Data

Penulis mengumpulkan data-data dan melakukan wawancara mengenai hal-hal yang berkaitan dengan penelitian.

d. Menentukan Kriteria

Penulis menentukan kriteria-kriteria dari sistem pendukung keputusan menggunakan metode Weighted Product (WP) dalam menentukan karyawan baru, diantaranya nilai tes wawancara, tes psikotes, tes kesehatan, pengalaman kerja, pendidikan terakhir, usia dan penampilan

e. Menentukan Bobot Preferensi

Penulis menentukan bobot preferensi atau tingkat kepentingan dari setiap kriteria.

f. Mengolah Data Perhitungan

Penulis mengolah data perhitungan yang sudah di tentukan dengan nilai kriteria dan nilai bobot preferensinya.

g. Saran dan Kesimpulan 
Penulis mengambil suatu kesimpulan berdasarkan analisis data-data yang terdapat pada pembahasan sebelumnya dan diperiksa apakah kesimpulan sesuai dengan hipotesis, maksud dan tujuan penelitian. Selain itu juga memberikan saran yang dapat digunakan sebagai masukan bagi lembaga sekolah terkait untuk dapat dimanfaatkan lebih lanjut.

\section{Instrument Penelitian}

Adapun jenis instrument yang digunakan dalam penelitian ini, yaitu:

a. Observasi

Metode ini diterapkan dengan mendatangi obyek perusahaan, yaitu salah satu PT. Hi-Lex Indonesia di Tangerang untuk mendapatkan data-data yang dibutuhkan.

b. Wawancara

Pengumpulan data dengan cara wawancara adalah usaha untuk mengumpulkan informasi dengan mengajukan beberapa pertanyaan secara lisan kepada HRD.

c. Studi Pustaka

Metode ini dilaksanakan dengan melakukan studi kepustakaan melalui membaca bukubuku, jurnal penelitian sejenis meupun e-book yang dapan mendukung penulisan tugas akhir ini, yaitu yang menjelaskan tentang Sistem Pendukung Kepuusan (SPK) dengan menggunakan metode Weighted Product (WP).

\section{Metode Pengumpulan Data, Populasi, dan Sampel Penelitian}

a. Metode Pengumpulan Data

Metode pengumpulan data yang dilakukan peneliti terbagi menjadi 2 (dua) cara, yaitu: dengan melakukan observasi langsung dan wawancara untuk mendapatkan data primer. data sekunder berasal dari mengumpulkan dan mengidentifikasi serta mengolah data tertulis berbentuk buku-buku dan jurnal yang berkaitan dengan penelitian.

b. Populasi dan Sampel Populasi

Populasi adalah wilayah generalisasi yang terdiri atas: obyek/subyek yang mempunyai kualitas dan karakteristik tertentu yang diterapkan oleh peneliti untuk mempelajari dan kemudian dutarik kesimpulannya.(Sugiyono, 2017)

Sampel adalah bagian dari jumlah dan karakteristik yang dimiliki oleh populasi tersebut.(Sugiyono, 2017) Dalam penelitian ini, penulis melakuan observasi dan wawancara langsung dengan HRD di salah satu perusahaan PT. Hi-Lex Indonesia di Tangerang. Populasi yang akan diambil pada salah satu divisi yang sedang memiliki 1 (satu) sampel calon karyawan yang akan diterima oleh perusahaan sebanyak 50 orang. Dari populasi tersebut akan diambil 10 (sepuluh) sampel.

\section{Metode Analisis Data}

Analisa adalah bagian penting dalam metodologi penelitian ilmiah, dikarenakan dengan melakukan analisis data tersebut dapat diberi arti dan makna yang berguna dalam suatu penyelesaian masalah. Metode Weighted Product (WP) merupakan metode pengambilan keputusan yang diperhitungkan secara kuantitatif (perhitungan matematika sesuai dengan rumus Weighted Product).

Langkah-langkah dalam perhitungan metode weighted product (WP) adalah sebagai berukut (Sari, 2018):

a. Menentukun kriteria-kriteria yang akan dijadikan acuan dalam pengambilan keputusan

b. Menentukan rating kecocokan setia alternatif pada setiap kriteria

c. Menentukan bobot referensi setiap kriteria

d. Mengalihkan seluruh atribut bagi sebuah alternatif dengan bobot sebagai pangkat positif untuk atribut keuntungan dan bobot berpangkat negatif untuk atribut biaya

e. Hasil perkalian tersebut dijumlahkan untuk mengahasilkan nilai vektor $\mathrm{V}$ untuk setiap alternatif

f. Mencari nilai alternatif dengan melakukan langkah yang sama seperti pada langkah 1 (satu), hanya saja menggunakan nilai tertinggi untuk setiap atribut tertinggi untuk setiap atribut manfaat dan nilai terendah untuk atribut biaya

g. Membagi nilai $\mathrm{V}$ bagi setiap alternatif dengan nilai standar

h. Mencari nilai alternatif ideal yakni dengan merangking nilai vektor $\mathrm{V}$ sekaligus membuat kesimpulan sebagai tahap akhir

Preferensi untuk alternatif Ai diberikan sebagai berikut (Pratiwi, 2016):

$W_{j}=\frac{w_{j}}{\sum W_{j}}$
$S_{i}=\prod_{j}^{n}=1 X_{i j}^{w j}$

Dimana :

$\mathrm{S}=$ Menyatakan preferensi alternatif dianalogikan sebagai vektor $\mathrm{S}$

$\mathrm{X} \quad=$ Menyatakan nilai kriteria

$\mathrm{w}=$ Menyatakan nilai bobot kriteria

$\mathrm{i} \quad=$ Menyatakan alternatif

$\mathrm{j} \quad=$ Menyatakan kriteria

$\mathrm{n} \quad$ = Menyatakan banyaknya kriteria

wj = Menyatakan pangkat bernilai positif untuk atribut keuntungan, dan bernilai negative untuk atribut biaya. 
Preferensi relatif dari setiap alternative, diberikan sebagai berikut:

$V_{i}=\frac{\Pi_{j}^{n}=1 X_{i j} w_{j}}{\Pi_{j}^{n}=1\left(X_{j^{*}}\right) w_{j}}$

\section{Dimana :}

$\mathrm{V}=$ Preferensi alternatif dianalogikan sebagai vektor $\mathrm{V}$

$\mathrm{X} \quad=$ Menyatakan nilai kriteria

$\mathrm{w}=$ Menyatakan bobot kriteria

$\mathrm{i} \quad=$ Menyatakan alternatif

$\mathrm{j} \quad=$ Menyatakan kriteria

$\mathrm{n} \quad$ = Menyatakan banyaknya kriteria

* = Banyaknya kriteria yang telah dinilai pada vektor S

\section{HASIL DAN PEMBAHASAN}

\section{Perhitungan dengan metode Weighted Product (WP)}

Perusahaan PT.Hi-Lex Indonesia pada bulan april 2019 membuka lowongan untuk 1 (satu) orang. Sebagai sampel perhitungan metode Weighted Product dalam seleksi penerimaan karyawan baru sebanyak 10 (sepuluh) pelamar yang akan diseleksi.

\section{Menentukan Bobot Kriteria}

Berikut menentukan bobot kriteria pada penerimaan karyawan baru PT. Hi-Lex Indonesia, terdapat 7 (tujuh) kriteria yang akan ditentukan, antara lain: Kriteria Tes Wawancara, Kriteria Tes Psikotes, Kriteria Tes Kesehatan, Kriteria Pengalaman Kerja, Kriteria Pendidikan Terakhir, Kriteria Usia, dan kriteria penampilan.

TABEL 1. DATA PELAMAR

\begin{tabular}{|c|c|c|c|c|c|c|c|c|}
\hline No & Nama & $\begin{array}{c}\text { Tes } \\
\text { Wawancara }\end{array}$ & $\begin{array}{c}\text { Tes } \\
\text { Psikotes }\end{array}$ & $\begin{array}{c}\text { Tes } \\
\text { Kesehatan }\end{array}$ & $\begin{array}{c}\text { Pengalaman } \\
\text { Kerja }\end{array}$ & $\begin{array}{l}\text { Pendidikan } \\
\text { Terakhir }\end{array}$ & Usia & Penampilan \\
\hline 1 & Sarinah & Cukup & $\begin{array}{l}\text { Sangat } \\
\text { Baik }\end{array}$ & Baik & 2 Tahun & D3 & $\begin{array}{c}22 \\
\text { Tahun }\end{array}$ & Sangat Baik \\
\hline 2 & Jilmah & Cukup & Buruk & Baik & 2 Tahun & S1 & $\begin{array}{c}21 \\
\text { Tahun }\end{array}$ & Sangat Baik \\
\hline 3 & Nuradiah & Baik & Buruk & Baik & 1 Tahun & S1 & $\begin{array}{c}21 \\
\text { Tahun }\end{array}$ & Baik \\
\hline 4 & $\begin{array}{l}\text { Iyan } \\
\text { Handoko }\end{array}$ & Baik & $\begin{array}{c}\text { Sangat } \\
\text { Baik }\end{array}$ & Baik & 0 Tahun & SMA & $\begin{array}{c}22 \\
\text { Tahun }\end{array}$ & Buruk \\
\hline 5 & Nurma & Cukup & Buruk & Baik & 0 Tahun & SMA & $\begin{array}{c}23 \\
\text { Tahun }\end{array}$ & Buruk \\
\hline 6 & Sulaiman & Sangat Baik & $\begin{array}{l}\text { Sangat } \\
\text { Baik }\end{array}$ & Sangat Baik & 1 Tahun & D1 & $\begin{array}{c}27 \\
\text { Tahun }\end{array}$ & Sangat Baik \\
\hline 7 & Rafli & Baik & Baik & Baik & 0 Tahun & SMA & $\begin{array}{c}22 \\
\text { Tahun }\end{array}$ & Sangat Buruk \\
\hline 8 & Nur Isnaini & Baik & Cukup & Sangat Baik & 3 Tahun & S1 & $\begin{array}{c}27 \\
\text { Tahun }\end{array}$ & Sangat Baik \\
\hline 9 & $\begin{array}{l}\text { Aprilia } \\
\text { Assyifa M.N }\end{array}$ & Cukup & Baik & Baik & 1 Tahun & D3 & $\begin{array}{c}21 \\
\text { Tahun }\end{array}$ & Sangat Baik \\
\hline 10 & Sukirman & Sangat Baik & $\begin{array}{c}\text { Sangat } \\
\text { Baik }\end{array}$ & Sangat Baik & $>3$ Tahun & $\mathrm{S} 1$ & $\begin{array}{c}28 \\
\text { Tahun }\end{array}$ & Baik \\
\hline
\end{tabular}

\section{Konversi Nilai Pelamar}

Menentukan rating alternatif pada setiap kriteria.

TABEl 2. Konversi Nilai Data PElamaR

\begin{tabular}{ccccccccc}
\hline \multirow{2}{*}{ No. } & \multirow{2}{*}{ Alternatif } & \multicolumn{7}{c}{ Nilai Kriteria } \\
\cline { 3 - 9 } & & C1 & C2 & C3 & C4 & C5 & C6 & C7 \\
\hline 1 & A1 & 3 & 5 & 4 & 3 & 3 & 2 & 5 \\
2 & A2 & 3 & 2 & 4 & 3 & 4 & 2 & 5 \\
3 & A3 & 4 & 2 & 4 & 2 & 4 & 2 & 4 \\
4 & A4 & 4 & 5 & 4 & 1 & 1 & 2 & 2 \\
5 & A5 & 3 & 2 & 4 & 1 & 1 & 3 & 2 \\
6 & A6 & 5 & 5 & 5 & 2 & 2 & 5 & 5 \\
7 & A7 & 4 & 4 & 4 & 1 & 1 & 2 & 1 \\
8 & A8 & 4 & 3 & 5 & 4 & 4 & 5 & 5 \\
9 & A9 & 3 & 4 & 4 & 2 & 3 & 2 & 5 \\
10 & A10 & 5 & 5 & 5 & 5 & 4 & 5 & 4 \\
\hline
\end{tabular}

Ket:

C1 : Tes Wawancara

C2 : Tes Psikotes

C3 : Tes Kesehatan

C4 : Pengalaman Kerja

C5 : Pendidikan Terakhir

C6 : Usia

C7 : Penampilan

\section{Tingkat Kepentingan}

Penentuan bobot berdasarkan nilai tingkat kepentingan masing-masing kriteria, tingkat kepentingan setiap kriteria dinilai dengan 1 sampai 5. Tingkat kepentingan dapat dilihat pada Tabel. 3 . 
TABEL.3. TINGKAT KEPENTINGAN

\begin{tabular}{cc}
\hline Tingkat Kepentingan & Nilai \\
\hline Sangat Rendah & 1 \\
Rendah & 2 \\
Cukup & 3 \\
Baik & 4 \\
Sangat Baik & 5 \\
\hline
\end{tabular}

Nilai bobot atau bobot awal (W) masingmasing kriteria telah ditentukan oleh pihak PT. HiLex Indonesia pada Tabel 4 dibawah ini.

TABEL .4. PEMBOBOTAN KRITERIA

\begin{tabular}{cc}
\hline Kode & Bobot \\
\hline C1 & 5 \\
C2 3 & 5 \\
C4 4 & 5 \\
C5 & 4 \\
C6 & 3 \\
C7 & 3 \\
\hline
\end{tabular}

\section{Perbaikan Bobot Perkriteria}

Setelah mendapatkan nilai bobot pada masing-masing kriteria, selanjutnya dilakukan perbaikan bobot dari nilai bobot awal. Untuk mendapatkan hasil tersebut dengan menggunakan perhitungan sebagai berikut:

a. Hasil untuk perhitungan bobot pada kriteria tes wawancara dengan nilai 5 adalah 0,17

b. Hasil untuk perhitungan bobot pada kriteria tes psikotes dengan nilai 5 adalah 0,17

c. Hasil untuk perhitungan bobot pada kriteria tes kesehatan dengan nilai 5 adalah 0,17

d. Hasil untuk perhitungan bobot pada kriteria pengalaman kerja dengan nilai 4 adalah 0,14

e. Hasil untuk perhitungan bobot pada kriteria pendidikan terakhir dengan nilai 3 adalah 0,10

f. Hasil untuk perhitungan bobot pada kriteria usia dengan nilai 3 adalah 0,10

g. Hasil untuk perhitungan bobot pada kriteria penampilan dengan nilai 4 adalah 0,14

Berikut merupakan ringkasan dari proses dari perhitungan hasil perbaikan bobot pada setiap kriteria pada Tabel 5, dibawah ini.

TABEL 5. BOBOT PREFERENSI

\begin{tabular}{cc}
\hline Bobot Kriteria & Nilai (W) \\
\hline C1 & 0,17 \\
C2 & 0,17 \\
C3 & 0,17 \\
C4 & 0,14 \\
C5 & 0,10 \\
C6 & 0,10 \\
C7 & 0,14 \\
\hline
\end{tabular}

\section{Perhitungan Nilai Vektor S}

Setelah dilakukan perbaikan bobot, dilakukan perhitungan nilai vektor (S), dengan memangkatkan dan mengalikan nilai masingmasing kriteria tersebut dengan bobot yang sudah diperbaiki sebelumnya, dengan perhitungan sebagai berikut:

a. Hasil perhitungan dari masing-masing kriteria pada alternatif 1 adalah 3,5055

b. Hasil perhitungan dari masing-masing kriteria pada alternatif 2 adalah 3,0874

c. Hasil perhitungan dari masing-masing kriteria pada alternatif 3 adalah 2,9690

d. Hasil perhitungan dari masing-masing kriteria pada alternatif 4 adalah 2,4876

e. Hasil perhitungan dari masing-masing kriteria pada alternatif 5 adalah 2,1110

f. Hasil perhitungan dari masing-masing kriteria pada alternatif 6 adalah 3,9489

g. Hasil perhitungan dari masing-masing kriteria pada alternatif 7 adalah 2,1735

h. Hasil perhitungan dari masing-masing kriteria pada alternatif 8 adalah 4,2094

i. Hasil perhitungan dari masing-masing kriteria pada alternatif 9 adalah 3,1888

j. Hasil perhitungan dari masing-masing kriteria pada alternatif 10 adalah 4,6636

Pada Tabel 6. merupakan penjelasan Preferensi Vektor S yaitu hasil nilai dari setiap alternatif serta jumlah total seluruh nilai vektor $\mathrm{S}$.

TABel 6. Nilai PREFERENSI VeKToR S

\begin{tabular}{cc}
\hline Preferensi Alternatif & Nilai Vektor S \\
\hline S1 & 3.5055 \\
S2 & 3.0874 \\
S3 & 2.9690 \\
S4 & 2.4876 \\
S5 & 2.1110 \\
S6 & 3.9489 \\
S7 & 2.1735 \\
S8 & 4.2094 \\
S9 & 3.1888 \\
S10 & 4.6636 \\
Total & 32.3447 \\
\hline
\end{tabular}

\section{Menghitung preferensi (Vi) untuk} Perangkingan

Menghitung preferensi prengkingan untuk mendapatkan nilai hasil dengan melakukan pembagian dengan rata-rata dari nilai setiap perkalian, dengan proses perhitungan sebagai berikut:

a. Hasil perhitungan vektor $\mathrm{V}$ pada alternatif 1 dengan nilai 3.5055 adalah 0,1084

b. Hasil perhitungan vektor $\mathrm{V}$ pada alternatif 2 dengan nilai 3.0874 adalah 0,0955 
c. Hasil perhitungan vektor $\mathrm{V}$ pada alternatif 3 dengan nilai 2.9690 adalah 0,0917

d. Hasil perhitungan vektor $\mathrm{V}$ pada alternatif 4 dengan nilai 2.4876 adalah 0,0769

e. Hasil perhitungan vektor $\mathrm{V}$ pada alternatif 5 dengan nilai 2.1110 adalah 0,0653

f. Hasil perhitungan vektor $\mathrm{V}$ pada alternatif 6 dengan nilai 3.9489 adalah 0,1221

g. Hasil perhitungan vektor $\mathrm{V}$ pada alternatif 7 dengan nilai 2.1735 adalah 0,0672

h. Hasil perhitungan vektor $\mathrm{V}$ pada alternatif 8 dengan nilai 4.2094 adalah 0,1302

i. Hasil perhitungan vektor $\mathrm{V}$ pada alternatif 9 dengan nilai 3.1888 adalah 0,0986

j. Hasil perhitungan vektor $\mathrm{V}$ pada alternatif 10 dengan nilai 4.6636 adalah 0,1442

Pada Tabel.7. merupakan ringkasan hasil nilai Vektor V pada setiap alternatif yang telah terhitung diatas.

TABel7. Preferensi Alternatif VeKTor V

\begin{tabular}{cc}
\hline Preferensi Alternatif & Nilai Vektor V \\
\hline V1 & 0,1084 \\
V2 & 0,0955 \\
V3 & 0,0917 \\
V4 & 0,0769 \\
V6 & 0,0653 \\
V7 & 0,1221 \\
V8 & 0,0672 \\
V9 & 0,1302 \\
V10 & 0,0986 \\
& 0,1442 \\
\hline
\end{tabular}

\section{Proses Perangkingan}

Proses hasil prengkingan seleksi administrasi yang sudah dilakukan beberapa perhitungan diatas maka didapatkan hasil seperti tabel 8. dibawah ini:

TABEl 8, HASIL PERANGKINGAN SELEKSI AdMINISTRASI

\begin{tabular}{cccc}
\hline No & Alternatif & Nilai Vektor V & Rangking \\
\hline 1 & A1 & 0,1084 & 4 \\
2 & A2 & 0,0955 & 6 \\
3 & A3 & 0,0917 & 7 \\
4 & A4 & 0,0769 & 8 \\
5 & A5 & 0,0653 & 10 \\
6 & A6 & 0,1221 & 3 \\
7 & A7 & 0,0672 & 9 \\
8 & A8 & 0,1302 & 2 \\
9 & A9 & 0,0986 & 5 \\
10 & A10 & 0,1442 & 1 \\
\hline
\end{tabular}


jurnal penelitian dengan pemilihan karyawan baru dengan menggunakan metode Weighted Product, bahwa metode tersebut lebih akurat mendapatkan hasil perhitungan bobot kriteria. Hasil perhitungan dengan menggunakan metode Weighted Product, dengan acuan kriteria tes wawancara, tes psikotes, tes kesehatan, pengalaman kerja, pendidikan terakhir, usia dan penampilan, maka terpilih 1 (satu) orang calon karyawan, yang bernama Sukirman yang akan menjadi karyawan di PT.HiLex Indonesia.

\section{Saran-saran}

Dari hasil penelitian yang dilakukan oleh penulis, maka dapat diusulkan beberapa saran untuk penelitian lanjutan sebagai berikut: Studi penelitian dapat dilakukan juga pada perusahaan lainnya dan dapat dikembangkan dengan metode penelitian seperti TOPSIS. Penelitian dapat dikembangkan lebih lanjut dengan kriteria-kriteria yang berbeda sesuai dengan kriteria dan bobot yang ditentukan perusahaan tempat dilakukannya penelitian. Semoga apa yang telah dihasilkan dalam penulisan ini dapat bermanfaat dan dapat membantu seorang atasan atau bagian HRD dalam pengambilan keputusan untuk menentukan calon karyawan yang akan diterima menjadi karyawan di PT. Hi-Lex Indonesia. Penulisan ini sangat jauh dari kata sempurna, oleh karena itu sangat diperlukan masukan, saran, dan kritik yang membangun dan dapat memperbaiki penelitian ini menjadi lebih baik.

\section{REFERENCES}

Agustin, Y. H., \& Kurniawan, H. (2015). SISTEM PENDUKUNG KEPUTUSAN PENILAIAN KINERJA DOSEN MENGGUNAKAN METODE WEIGHTED PRODUCT (STUDI KASUS : STMIK PONTIANAK) | Agustin | Seminar Nasional Informatika (SNIf). In Seminar Nasional Informatika (pp. 177-182). LPPM Universitas Potensi Utama. Retrieved from http://ejournal.potensi-

utama.ac.id/ojs/index.php/SNIf/article/view $/ 261$

Amalia, R. M., \& Utami, D. Y. (2018). PEMBERIAN REWARD BERDASARKAN PENILAIAN KINERJA KARYAWAN DENGAN METODE AHP PADA PT. ANUGERAH PROTECINDO. Jurnal Ilmu Pengetahuan Dan Teknologi Komputer, 3(2), 181-188.

Ariani, F. (2017). Sistem Penunjang Dalam
Penentuan Prioritas Pemilihan Percetakan Media Promosi Menggunakan Metode AHP. Jurnal Informatika, 4(2). https://doi.org/10.31311/JI.V4I2.2122

Fajarianto, O., Iqbal, M., \& Cahya, J. T. (2017). Sistem Penunjang Keputusan Seleksi Penerimaan Karyawan Dengan Metode Weighted Product. Jurnal Sisfotek Global, 7(1), 49-55. Retrieved from http://journal.stmikglobal.ac.id/index.php/si sfotek/article/view/128

Ismail, \& Nurjaya. (2016). Seleksi Penerimaan Karyawan Baru Menggunakan Metode WP (Weighted Produck) Dengan Bahasa Pemrograman PHP Dan MYSQL. Jurnal Informatika Universitas Pamulang, 1(1), 2832. Retrieved from http://openjournal.unpam.ac.id/index.php/i nformatika/article/view/1465

Mirawati, Hikmah, A. B., \& Wiguna, W. (2018). Sistem Penunjang Keputusan Penilaian Kinerja Kasir Lotte Mart Menggunakan Metode Weighted Product. IJCIT (Indonesian Journal on Computer and Information Technology), 3(2), 186-196.

Moenir, A., \& Budiyanto, S. (2018). PENERAPAN METODE WEIGHTED PRODUCT (WP) BERBASIS WEB UNTUK PEMILIHAN KETUA PADA DEWAN KERJA GERAKAN PRAMUKA KWARTIR CABANG KOTA TANGERANG. In Seminar Nasional Informatika dan Sistem Informasi (pp. 84-96). Tangerang Selatan: Universitas Pamulang. Retrieved from http://openjournal.unpam.ac.id/index.php/S NISIS/article/view/3070

Pratiwi, H. (2016). Buku Ajar Sistem Pendukung Keputusan. Yogyakarta: Deepublisher.

Putra, C. I., \& Ferdiansyah, F. (2018). Implementasi Dan Pembuatan Sistem Penunjang Keputusan Penerimaan Karyawan Di Pt Genesis Indotama Teknologi Menggunakan Metode Weighted Product Berbasis Web. SKANIKA, 1(3), 987-994. Retrieved from http://jom.fti.budiluhur.ac.id/index.php/SKA NIKA/article/view/2500

Rahmawati, A., \& Astuti, Y. (2018). Implementasi Weighted Product Untuk Penerimaan Karyawan. Jurnal Mantik Penusa, 2(1), 28-34. Retrieved from http://ejurnal.pelitanusantara.ac.id/index.php/manti 
$\mathrm{k} /$ article/view/321

Sari, F. (2018). Metode Dalam Pengambilan Keputusan. (S. Novidiantoko \& H. A. Susanto, Eds.) (Buku). yogyakarta: Deepublish
Publisher.

Sugiyono. (2017). METODE PENELITIAN KUANTITATIF, KUALITATIF, DAN R\&D (Buku). Bandung: ALFABETA. 